\title{
As tecnologias da informação e da comunicação na formação de professores
}

\author{
Raquel Goulart Barreto \\ Glaucia Campos Guimarães \\ Ligia Karam Corrêa de Magalhães
}

Universidade do Estado do Rio de Janeiro, Programa de Pós-Graduação em Educação

Elizabeth Menezes Teixeira Leher

Universidade Federal do Rio de Janeiro, Núcleo de Tecnologia Educacional para a Saúde

\section{Contextualização}

Este texto corresponde a um recorte do estado do conhecimento em educação e tecnologia, produzido a partir de 331 documentos (242 dissertações, 47 teses e 42 artigos) elaborados entre 1996 e $2002 .{ }^{1}$ Ainda que, nos limites deste artigo, as múltiplas dimensões do estudo mais amplo não sejam objeto de discussão, dois aspectos parecem necessários à compreensão do presente recorte.

O primeiro deles está relacionado à própria configuração do estudo. De um lado, a condição de estado do conhecimento suscita a expectativa de mapeamento de uma área de saber. De outro, a área específica (educação e tecnologia) torna mais complexo o atendimento a essa expectativa, não apenas por ser nova, por estar em processo de configura-

${ }^{1}$ Pesquisa financiada pelo Instituto Nacional de Estudos e Pesquisas Educacionais Anísio Teixeira (INEP) e realizada pela ANPEd, em 2004, por equipe integrada pelas autoras deste artigo e Nilda Guimarães Alves, da qual resultou um relatório a ser publicado pelo INEP. ção, mas por compreender território difícil de delimitar, caracterizado por muitos deslocamentos de centro e margens, relacionados à objetivação das tecnologias mesmas e da sua incorporação educacional, bem como aos espaços de lugares e de fluxos envolvidos (Oliveira, 2001). Cabe registrar que, nessa área, por conta das discussões paradigmáticas, a própria noção de mapeamento pode ser objeto de contestação. Diante desse quadro, a alternativa foi buscar traçar uma panorâmica, apontando tendências que possam vir a favorecer a consolidação dos estudos marcados pelo movimento de aproximação de educação e tecnologia, mais precisamente das tecnologias da informação e da comunicação (TIC), implicando modos de recontextualização das últimas na primeira (Bernstein, 1990).

O segundo aspecto, indissociável do primeiro, diz respeito à presença da quantificação, notadamente no que tange à freqüência de elementos e relações nos documentos pesquisados. Por sua vez, os aspectos quantitativos, em si, imprescindíveis ao mapeamento de tendências, não podem dar conta das diferentes questões envolvidas. São importantes porque referidos a uma matriz interpretativa a que, a rigor, a 
própria coleta dos dados já responde. Em outras palavras, os aspectos quantitativos sustentam os movimentos analíticos que materializam a abordagem da dimensão qualitativa do estudo.

Para explicitar o modo de construção do objeto no estudo aqui recortado, é oportuno o registro dos seus vários movimentos: levantamento no portal da Coordenação de Aperfeiçoamento de Pessoal de Nível Superior (CAPES); desenvolvimento de estratégias de acesso aos textos propriamente ditos, viabilizado em mais de $90 \%$ dos casos; elaboração de resumos ampliados, com base no modelo da Red Latinoamericana de Documentación e Información en Educación (REDUC), a partir da leitura dos textos; discussão dos pontos de entrada no conjunto da produção; e identificação de elementos e de relações definidoras das tendências buscadas.

Os dois últimos movimentos não obedeceram a uma seqüência necessariamente linear no processo de construção, marcado por idas e vindas, ratificações e retificações. Apenas estão assim sistematizados neste artigo visando a favorecer a sua leitura. Com o mesmo objetivo, é importante antecipar que foram buscados os seguintes elementos: tecnologias privilegiadas; tipos de estudo; contextos de aplicação; modalidades de ensino; abordagens; e referências bibliográficas. Para tentar dar conta das relações entre eles, foram analisados: os focos constitutivos das produções individualmente consideradas; as referências teórico-metodológicas específicas; as palavras-chave como pontos de entrada no conjunto da produção; e os cruzamentos dos itens anteriores.

Cabe ainda explicitar que os focos foram estabelecidos pela aplicação de critérios sucessivos, sendo o primeiro deles o de amplitude. Nesse primeiro momento, foram identificados três blocos de teses e dissertações (T\&D): as discussões em nível macro, objetivando as políticas e propostas de inserção das TIC, subdivididas em concepção de sociedade e paradigma educacional; as várias inserções das TIC no processo de ensino-aprendizagem como um todo (denominadas TIC no ensino), distribuídas pelas modalidades: presencial, a distância (EAD), ${ }^{2}$ e virtual; ${ }^{3}$ e os usos específicos, traduzidos em aplicações tópicas, na medida em que centrados em determinados suportes, necessidades ou conteúdos.

É possível verificar que, em termos de freqüência, as T\&D analisadas tratam especialmente das TIC no ensino. São 186 estudos (64\% do total), elaborados a partir de focalizações que podem ser sintetizadas na incorporação das TIC: à formação de professores (FP), nas suas mais variadas configurações: inicial e continuada, presencial e a distância, como formação e capacitação; e às práticas desenvolvidas nos diferentes espaços pedagógicos, seja na condição de ferramentas ou instrumentos, seja na perspectiva do redimensionamento, seja, ainda, em propostas de virtualização dos processos mesmos, privilegiando a aprendizagem por meios eletrônicos.

Em busca dos sentidos atribuídos à presença das TIC, abrangendo desde as novas possibilidades agregadas às práticas pedagógicas, à reconfiguração dessas práticas e do conjunto de reflexões sobre elas, foram assumidas duas questões inextricavelmente relacionadas: os modos pelos quais as referidas práticas são objetivadas nas T\&D; e as relações entre educação e tecnologia que lhes dão sustentação.

\section{O recorte}

Desse conjunto de $186 \mathrm{~T} \& \mathrm{D}$, recortamos as 88 (11 teses e 77 dissertações) centradas na incorporação das TIC na/para a formação de professores, correspondentes a 30\% do total (289) e quase à metade (47\%) dos estudos voltados para a incorporação das TIC às práticas pedagógicas. O elevado número de T\&D acerca da FP, verificável no percentual que representam no conjunto dos estudos em que se baseia o presente recorte, pode atestar a relevância da temática privilegiada. Mais ainda, são os sentidos dessa

\footnotetext{
2 Designando educação a distância e ensino a distância.

${ }^{3}$ Em termos gerais, compreendida como aprendizagem por
} meios eletrônicos. 
representação que merecem destaque, já que se trata da formação dos profissionais da educação e já que as $\mathrm{T} \& \mathrm{D}$, como já foi dito, focalizam as diferentes configurações dessa formação.

Em se tratando dos sentidos postos em circulação nas/pelas T\&D, é importante explicitar que as buscas assinaladas ao final da seção anterior remetem a uma dimensão discursiva. O conteúdo das T\&D, compreendido pelas questões nelas encaminhadas, não deixa de circunscrever um discurso pedagógico: das e sobre as práticas em que as TIC são incorporadas. As escolhas lexicais, por exemplo, materializam, na superfície lingüística, os movimentos de configuração dos estudos na área, que, no caso, pode ser identificada como educação $e$ tecnologia, nos termos da adição como marca da distância e das tentativas de aproximação de áreas distintas, ou como tecnologia(s) $n a$ educação, pensando a sua objetivação em contexto específico. Do ponto de vista deste artigo, a escolha está marcada no título: na formação de professores.

Além disso, também é importante assinalar que este estudo não teve a pretensão de dar conta da análise dos discursos das $\mathrm{T} \& \mathrm{D}$, individualmente e em conjunto. Pistas lingüísticas foram seguidas no sentido de dimensionar o seu conteúdo, assim como as referências contextuais foram buscadas para situar as questões nelas detectadas, partindo de dois pressupostos: 1) a linguagem não é transparente; e 2) o movimento dos sentidos é dimensionado pela relação linguagem-história ou, nas palavras de Fairclough (2001), nas relações entre discurso e mudança social.

Assim como André (2002), no estudo relativo à formação de professores no Brasil (1990-1996), introduziu a análise de conteúdo empreendida pela expressão: "o que dizem as dissertações e teses", buscamos um subtítulo que expressasse a trajetória empreendida, partindo da delimitação do lugar e das condições do nosso dizer: o que foi lido nas teses e dissertações acerca das TIC na FP. Com ele, a pretensão é ratificar que o dito aqui se baseia nas $\mathrm{T} \& \mathrm{D}$, sem desconsiderar os processos de negociação de sentidos que constituem a leitura (Barreto, 2002).

\section{O que foi lido nas teses e dissertações acerca das tecnologias da informação e da comunicação na formação de professores}

O lugar e as condições do dizer a respeito deste mapeamento das T\&D que tratam das TIC na FP são introduzidos pela sua distribuição ano a ano:

\section{Gráfico 1 - Distribuição das T\&D por ano}

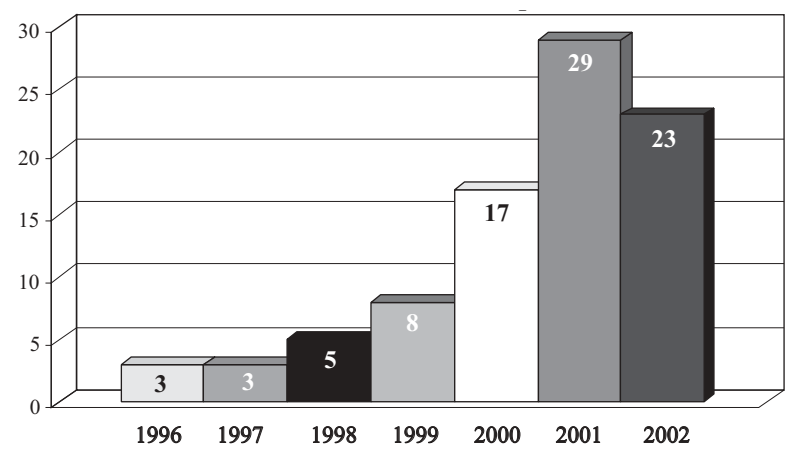

Nesta primeira aproximação, é digno de nota o aumento das T\&D no período recortado. De 1996 a 1999, estão apenas 19 dos documentos analisados, enquanto de 2000 e 2002 eles são 69. A rigor, um aumento previsível, considerando pelo menos duas condições contextuais: o fato de que o período é marcado pela presença crescente das TIC no conjunto das práticas sociais e pela implementação de políticas visando à sua incorporação educacional.

Os marcos em que esse aumento significativo está inscrito, notadamente no que tange à FP, são caracterizados por Fonseca (1998, p. 41): “o ano de 1995 pode ser visto como um divisor das recomendações e 'condicionalidades' para a concessão de créditos e a aplicação de sanções pelo seu descumprimento". Entre elas, estão as propostas de formação de professores a distância.

Também em 1995 é criada a Secretaria de Educação a Distância no Ministério da Educação (SEED/ $\mathrm{MEC}$ ), cuja nomeação traduz o privilégio de um modo de incorporação educacional das TIC, na condição de estratégia de formação pela via do EAD, prevendo programas específicos para esse fim. Em março de 1996, entra no ar a TV Escola. Em 1997, é criado o 
Programa Nacional de Informática na Educação (PROINFO). Ainda em 1997, é instituído o Programa de Apoio à Pesquisa em Educação a Distância (PAPED), em parceria com a CAPES, com o apoio da Organização das Nações Unidas para Educação, a Ciência e a Cultura (UNESCO). ${ }^{4}$

Esses marcos apontam para condições bastante favoráveis à elaboração de estudos das TIC: programas em âmbito nacional para a incorporação das TIC ao ensino (TV Escola e PROINFO) e apoio financeiro para a realização de pesquisas, configurando, sob os auspícios dos organismos internacionais, demanda induzida.

De que tecnologias tratam as T\&D

Gráfico 2 - As tecnologias privilegiadas

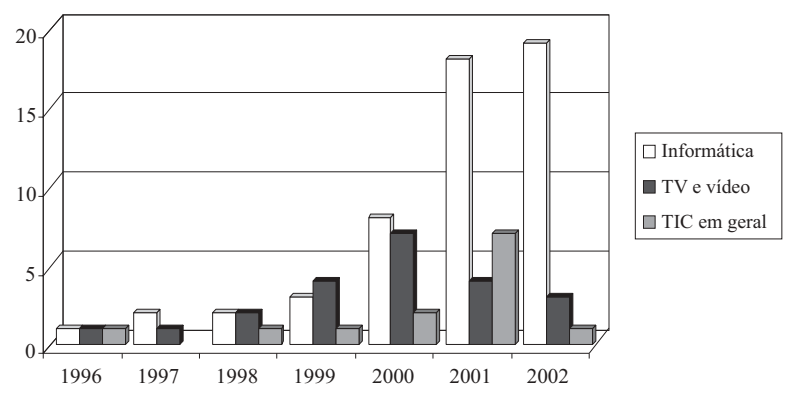

Nesse gráfico, é possível confirmar a hipótese de trabalho de que as tecnologias da informática são as mais presentes e descrevem curva sempre ascendente. Com o pico das produções localizado no ano de 2001, esse é o único aspecto em que não há decréscimo em 2002.

Televisão e vídeo aparecem em um crescendo até 2000, apresentando queda significativa nos anos subseqüentes. Em sua maioria, as T\&D tratam da TV Escola e de outros programas voltados para a utilização de televisão e vídeo, com vista à formação de professores a distância. Apenas duas delas trabalham

${ }^{4}$ Datação que também pode explicar, pelo menos em parte, o pico de 2001, considerando os prazos para a integralização dos cursos de mestrado e doutorado. especificamente as possibilidades representadas pela sua utilização no ensino presencial.

O quadro é completado pelas T\&D que, não se detendo em tecnologias específicas, trabalham aspectos do próprio movimento de recontextualização das TIC na FP. São as menos numerosas, ainda que também marcadas por destacado aumento em 2001, cerca de quatro ou cinco anos após a criação da SEED/ MEC e a implantação dos seus programas principais.

\section{Como as T\&D abordam as TIC na FP}

É evidente a predominância da abordagem qualitativa (85\%), tendência que pode ser verificada nas ciências humanas como um todo. São extremamente raras as abordagens quantitativas (2\%). Como uma tentativa de síntese das anteriores, foram analisados estudos que se afirmam quanti-qualitativos e/ou qualiquantitativos (13\%), com a denominação marcando a ênfase posta e, nesses termos, indicando que a síntese ainda está por ser alcançada.

Quanto à configuração teórico-metodológica assumida, é importante observar que quase a metade das T\&D corresponde a estudos de caso, embora essa denominação algumas vezes pareça esvaziada, na medida em que indiscriminadamente utilizada, chegando a sugerir uma espécie de "guarda-chuva" para abrigar os mais diversos estudos pontuais. Também são frequientes movimentos de pesquisa-ação e estudos avaliativos. Em relação às demais possibilidades, a dispersão é bastante grande, conforme o gráfico a seguir:

Gráfico 3 - Percentual: Tipos de estudo

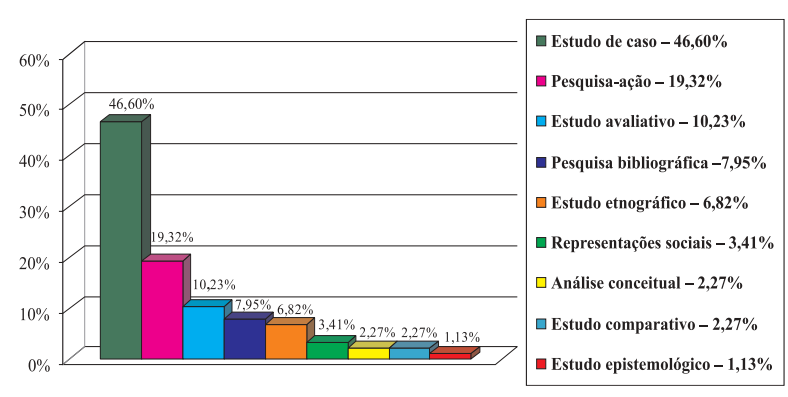


Cabe ainda observar que essa classificação foi feita com base nas afirmações constantes das T\&D. Somente nos casos em que não havia, por parte dos autores, identificação clara do tipo de estudo empreendido, foi verificada a sua correspondência/pertinência a um dos tipos listados.

As referências assumidas nas/pelas T\&D

$\mathrm{Na}$ esmagadora maioria das $\mathrm{T} \& \mathrm{D}$, predominam as referências nacionais (91\%), suscitando a discussão de pelo menos dois aspectos, estreitamente relacionados à dispersão caracterizada anteriormente. Por um lado, a existência, no Brasil, de expressiva produção consolidada na área. Por outro, os fatores ligados à acessibilidade das produções, incluídas aí as possíveis barreiras lingüísticas.

As referências bibliográficas mais presentes são: Lévy, Morin, Schaff, Castells, Piaget, Vygostky, Papert, Babin, Freire, Valente, Kenski, Pretto e Belloni. Como é possível verificar, alguns autores citados se caracterizam pela abordagem das TIC dentro e fora dos contextos educacionais. Outros, sequer abordam questões relacionadas às TIC, até por impossibilidade histórica, como Piaget, Vygostky e Freire. No caso, suas obras são tomadas para a ancoragem das TIC na educação, tendo por base as concepções acerca de aprender-ensinar.

\section{As focalizações que caracterizam as T\&D}

Tomando o conjunto das T\&D agrupadas em TIC no ensino, a partir da aplicação do critério de abrangência, foram produzidos desdobramentos que, por sua vez, resultaram em novos subgrupos, concernentes às modalidades de ensino e, finalmente, aos contextos de aplicação (EAD) e/ou aos sentidos atribuídos à inserção das TIC (ensino presencial).

Da aplicação dos novos critérios, resultou a distribuição ano a ano que constitui a Tabela 1.

As T\&D centradas nas TIC na/para a FP evidenciam a ênfase na formação a distância, que pode ser explicada pelo investimento maciço nessa modalidade de ensino e pela recontextualização redutora das TIC proposta pelo MEC, ao criar a SEED para dar conta desse movimento. A distribuição representada anteriormente parece dar conta da demanda induzida referida, já que são 52 T\&D, em um universo de 88 (cerca de $60 \%$ ), centradas nas TIC para a FP a distância. Contudo, também parece corroborada a tendência de superar a identificação restritiva das TIC à EAD, igualmente indicada na nova caracterização do PAPED, ${ }^{5}$ ainda que a sua denominação original permaneça.

Tabela 1 - Distribuição das

T\&D na FP - 1996-2002

\begin{tabular}{|c|c|c|c|c|c|c|c|c|c|c|}
\hline Focos & & Ano & 1996 & 997 & 1998 & 1999 & 2000 & 2001 & 2002 & Tota \\
\hline \multirow{7}{*}{$\begin{array}{l}\text { TIC no } \\
\text { ensino }\end{array}$} & \multirow{4}{*}{$E A D-F P$} & TV escola & 0 & 0 & 0 & 2 & 4 & 4 & 3 & 13 \\
\hline & & PROINFO & 0 & 0 & 0 & 0 & 2 & 5 & 4 & 11 \\
\hline & & \begin{tabular}{|l|} 
Outros \\
programas
\end{tabular} & 1 & 1 & 2 & 2 & 2 & 5 & 1 & 14 \\
\hline & & $\begin{array}{l}\text { Cursos } \\
\text { específicos }\end{array}$ & 1 & 1 & 1 & 2 & 3 & 5 & 1 & 14 \\
\hline & \multirow[b]{2}{*}{ Presencial } & Ferramentas & 0 & 0 & 0 & 1 & 0 & 1 & 4 & 6 \\
\hline & & \begin{tabular}{|l|} 
Redimen- \\
sionamento
\end{tabular} & 0 & 1 & 1 & 1 & 3 & 6 & 2 & 14 \\
\hline & \multicolumn{2}{|c|}{ Virtualização do ensino } & 1 & 0 & 1 & 0 & 3 & 3 & 8 & 16 \\
\hline \multicolumn{3}{|c|}{ Total } & 3 & 3 & 5 & 8 & 17 & 29 & 23 & 88 \\
\hline
\end{tabular}

Nessa mesma tabela, é possível verificar que, a despeito do privilégio atribuído à EAD, está configurado significativo espaço do ensino presencial e que, neste, a tendência aponta no sentido da incorporação das TIC para o redimensionamento do processo ensino-aprendizagem, sugerindo superação da perspectiva tecnicista, centrada na concepção das TIC como ferramentas e instrumentos. Nessa distribuição, o foco mais freqüente nas $\mathrm{T} \& \mathrm{D}$ corresponde à incorporação das TIC para o redimensionamento do processo de ensino-aprendizagem, sugerindo, mais do que uma simples presença favorecedora da consecução dos mesmos objetivos, a possibilidade de que sua recontextualização instaure diferenças qualitativas no processo de formação globalmente considerado.

\footnotetext{
${ }^{5}$ Cf. <http://www.capes.gov.br/capes/portal/conteudo/10/
} PAPED.htm>. 
Em contrapartida, os números absolutos parecem não expressar a tendência mais atual dos estudos na área. Nos últimos anos do período pesquisado (20002002), adquirem relevo propostas de "virtualização" do ensino, expressando a aprendizagem por meios eletrônicos, redimensionando as categorias tempoespaço e, nesses termos, apontando para a ruptura com a demarcação da sala de aula e da escola, pelo menos na configuração histórica conhecida por todos.

Esse movimento está representado no Gráfico 4, a seguir.

\section{Gráfico 4 - Foco das T\&D por ano}

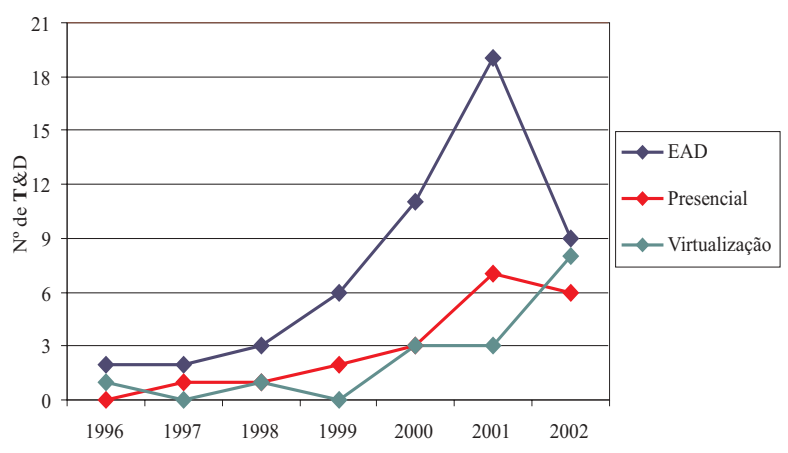

A partir da leitura das $\mathrm{T} \& \mathrm{D}$, foram identificadas as características definidoras do chamado ensino virtual, em um movimento de dupla diferenciação: (1) da EAD pela (ao menos suposta) ruptura com a lógica distributivista; e (2) do ensino presencial pelo modus operandi, tanto no que concerne à mediação do professor, quanto aos ambientes em que pode ser desenvolvida.

Para chegar a essa definição, foram analisadas as palavras-chave na/da leitura das T\&D.

\section{As palavras-chave na/da leitura das $T \& D$}

No que diz respeito às palavras-chave, é preciso esclarecer que, do ponto de vista analítico adotado, não se restringem às definidas pelos autores e registradas no banco de dados da CAPES, mas incluem expressões que podem esclarecer as tendências a serem analisadas, com base nas leituras que sustentaram a produção dos resumos analíticos.
As palavras e expressões foram destacadas como as escolhas lexicais dos autores das T\&D e, portanto, como pontos de entrada para os modos de objetivação das TIC no ensino e, mais especificamente, para/ na formação de professores. Do ponto de vista quantitativo, foram levantadas a partir da sua recorrência nas três modalidades de ensino identificadas: EAD; presencial; e virtual, ou tendente à virtualização. São elas:

Educação a distância, a mais recorrente das expressões, refere-se à EAD para a formação continuada de professores para os mais diversos níveis, da educação básica ao ensino superior, sendo defendida como: alternativa metodológica; garantia de formação com qualidade; formação em serviço que visa à articulação teoria-prática; e formação cooperativa.

Outras palavras recorrentes são: capacitação, atualização, qualificação e treinamento, referindose a cursos de formação continuada, sejam estes presenciais ou a distância. As três primeiras remetem a discussões sobre pressupostos situados na área semântica da incapacidade; treinamento, por sua vez, aponta para uma perspectiva restritiva do que seria a formação.

Multiplicador, facilitador, tutor e animador são termos que substituem professor, redefinindo suas funções em perspectiva igualmente restritiva, nesse contexto em que a expressão trabalho docente também cede lugar a tarefas e atividades docentes. Nesses termos, o que as formulações acerca das TIC na EAD tendem a sugerir é uma espécie de facilitação dos processos "formativos".

No que se refere aos produtos, a palavra competência, ainda que menos freqüente, aparece como chave importante, tendo em vista que presente como: noção, por vezes com a reivindicação do estatuto de conceito; princípio de organização curricular; e mecanismo para a certificação.

O desenvolvimento de competências e habilidades está diretamente ligado a outras palavras-chave presentes nas T\&D: os meios e os recursos. As tecnologias interativas são apontadas como responsáveis por mudanças estruturais na FP. Dentre os meios e 
recursos, são destacados: o rádio, a televisão, o vídeo e, principalmente, o computador. Neste, merecem destaque: chat, correio eletrônico, hipermídia/hipertexto, home page, Internet, lista de discussão e videoconferência, trabalhados como métodos de instrução, apoio e suporte às tarefas docentes.

É possível observar a ausência de referências às tecnologias há muito apropriadas pela escola, a ponto de serem ditas "educacionais", mesmo quando as T\&D se reportam ao ensino presencial. Parece que estas foram simplesmente descartadas, apagadas e substituídas pela informática, pelos multimeios e pelas novas mídias, em nome da atratividade e da interatividade. Em geral, as chamadas novas tecnologias são associadas a mudanças estruturais e, ao mesmo tempo, desvinculadas das condições materiais dos contextos educacionais, mesmo quando a EAD é defendida como única alternativa de acesso às TIC.

$\mathrm{O}$ acesso, a inserção, a implantação e, mais raramente, a apropriação das TIC estão postos no sentido de inovar/modernizar os processos educacionais, em geral, e os de formação docente, em particular. Na maioria das vezes, o acesso às TIC é a tônica assumida nas T\&D, sem o questionamento dos modos e dos sentidos do acesso.

As redes são uma metáfora-chave, especialmente na abordagem das produções relacionadas à virtualização do ensino, na medida em que sustentam as concepções de colaboração e cooperação, ultrapassando projetos elaborados por especialistas e distribuídos em broadcasting (Pretto, 2002).

Finalmente, ambientes de aprendizagem estão referidos a: laboratório de informática, laboratório de EAD, espaço virtual, ambiente web, comunidade virtual, ciberespaço. É essa a expressão que, nas T\&D, sustenta a proposição de outros espaços de aprendizagem, na ruptura com o conceito físico e na constituição fora dos limites da sala de aula e da escola.

\section{Uma análise de tendências}

A leitura das T\&D defendidas no período recortado (1996-2002) permitiu identificar pelo menos duas tendências diretamente ligadas às modalidades de ensino e aos contextos de aplicação das TIC: o privilégio da abordagem da formação de professores por meio da EAD; e a proposta da virtualização do ensino, como movimento expresso pelas propostas verificadas na construção dos objetos de estudo ou, ainda, nas conclusões e recomendações dos trabalhos.

\section{A abordagem da EAD}

No que se refere à tendência de focalizar a FP a distância, que soma mais da metade (55 em 88) das $\mathrm{T} \& \mathrm{D}$, a consideração inicial é a sua vinculação à proposta do MEC para a incorporação das TIC, explicitada na seção anterior. A partir daí, é preciso interrogar a EAD de que tratam as T\&D.

Retomando a Tabela 1, é possível verificar que os estudos estão centrados em programas com a chancela ministerial (TV Escola e PROINFO), em programas outros, sejam eles mais ou menos relacionados aos primeiros, e, ainda, em cursos específicos. Se esse é, por assim dizer, o conteúdo das T\&D que tratam da EAD na formação de professores, é preciso investigar a contextualização desses programas e cursos nesse processo.

Algumas das T\&D localizam programas e cursos na formação inicial dos professores, como demonstra o Gráfico 5:

Gráfico 5 - Relação entre modalidades de ensino e formação inicial

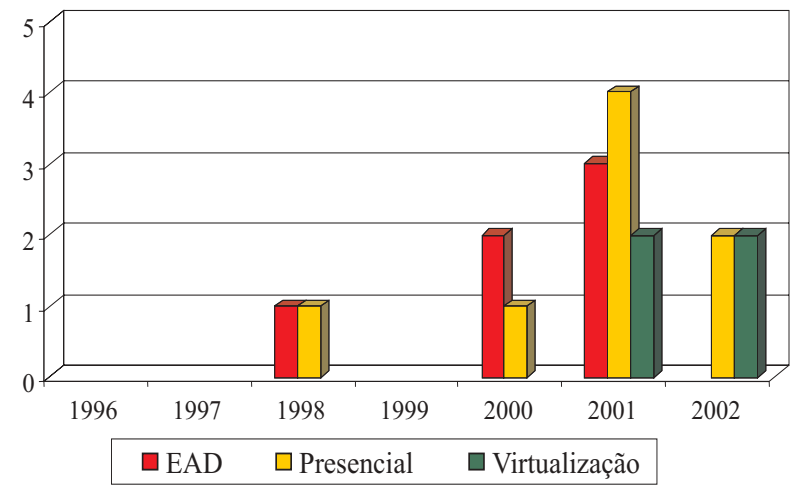


Já a grande maioria se refere ao contexto da formação continuada: ${ }^{6}$

Gráfico 6 - Relação entre modalidades de ensino e formação continuada

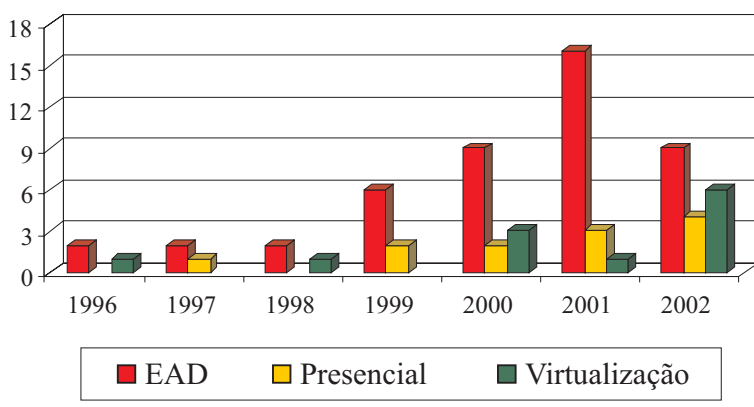

Neste ponto, vale lembrar que podem ser levantadas algumas objeções à caracterização de programas como o TV Escola e o PROINFO como sendo de EAD. No entanto, as T\&D não as assumem. Algumas até as registram, mas seguem na direção da sua análise como EAD.

Assim, é importante caracterizar as trajetórias empreendidas nas $\mathrm{T} \& \mathrm{D}$ centradas na EAD para a FP, compreendendo pressupostos, abordagens e conclusões e recomendações. Nesse sentido, é possível mapear duas trajetórias que, no limite, demarcam pólos opostos, sem deixar de reconhecer a existência de nuanças no entremeio.

A primeira dessas trajetórias parte do pressuposto de que a EAD, desde que tecnicamente bem elaborada, pode sustentar o desenvolvimento de "programas de capacitação" economicamente mais viáveis do que os presenciais, permitindo o crescimento exponencial do número de formados, capacitados, qualificados, atualizados e/ou treinados. Nessa linha, os trabalhos geralmente concluem ou sugerem que a EAD seja uma alternativa metodológica viável para a formação continuada e, em menor escala, para a ini-

${ }^{6}$ É de se esperar que pesquisas futuras indiquem mudança neste quadro, considerando a atual política de disseminação da formação inicial a distância. cial. Em ambos os casos, sugerem que a EAD inclua momentos presenciais.

As T\&D voltadas para a EAD contemplam a análise de programas, mas empreendem movimentos diversos. Algumas objetivam os programas em si, destacando aspectos relativos à sua concepção, incluindo seus pressupostos, ao modus operandi projetado, aos materiais que os sustentam etc. Outras incluem discussões relativas a lacunas entre o discurso modernizador que justifica esses programas e a ausência de condições objetivas que favoreçam a sua implementação. Todas incluem críticas mais ou menos sistemáticas aos programas analisados, distinguindo-se pela presença ou ausência de sugestões de reformulação. Dito de outro modo, as T\&D inscritas nessa linha tendem a enfatizar as contribuições dos programas de EAD para a "capacitação" de professores, ainda que sugiram a reformulação dos aspectos "frágeis" detectados.

É digno de nota, ainda, o movimento de fundamentar a FP, inicial ou continuada, em competências, na condição de princípio de organização e critério de avaliação. Em outras palavras, as T\&D tendem a pensar as TIC na EAD com base nas competências e habilidades que, somadas, apontam para (em alguns casos a idéia é a de que "garantem") o desempenho docente projetado.

A trajetória oposta parte do pressuposto de que a EAD reduz a FP à capacitação, qualificação, atualização e ao treinamento, sendo, portanto, insatisfatória. As T\&D aí agrupadas, em número inferior às da trajetória anterior, tendem a apresentar argumentos políticos em nível macro, como a concepção dos programas de EAD no contexto de uma proposta de "globalização" excludente e do atendimento às exigências do mercado. As conclusões que apresentam dizem respeito ao fato de que, ante as múltiplas dimensões da FP (seja inicial ou continuada), não há como reduzi-la à EAD, explicitando que o alvo deve ser a formação propriamente dita, não reduzida a uma capacitação que, por sua vez, signifique apenas certificação.

As T\&D aí agrupadas sugerem maior investimento na formação inicial, destacando a qualidade impli- 
cada no conceito mesmo de formação e apontando no sentido da superação da razão instrumental, tecnicista, no trabalho com as TIC. Tendem a concluir pela necessidade de fortalecimento da dimensão didáticopedagógica da formação, de modo que favoreça uma postura crítica e consciente diante das TIC, visando, em última análise, à sua apropriação e ao conseqüente redimensionamento do trabalho docente. Indicam a possibilidade de diminuir o descompasso tempo/ espaço entre as práticas sociais e escolares, apontando em direção oposta à substituição tecnológica.

As recomendações presentes nesse conjunto de T\&D podem ser sintetizadas na promoção das condições objetivas para a apropriação visada, com base em duas críticas: à ausência de recursos alocados na formação inicial presencial, impedindo que os professores formados tenham uma história de apropriação das TIC e, em alguns casos, sequer de acesso a elas; e às simplificações que têm marcado a formação a distância, quer inicial, quer continuada, em que a presença das TIC pode ser valorizada como um fim em si mesma, desconsiderando os modos de acesso viabilizado. Em suma, enquanto alguns podem não ter sequer acesso às TIC, outros podem tê-lo em condições bastante restritivas, obstaculizando o redimensionamento do trabalho realizado com elas.

\section{As relações entre ensino presencial e virtual}

Também é importante focalizar outra tendência relacionada às modalidades de ensino, apontada na Figura 4. Como é possível verificar, no final do período contemplado por esta investigação os estudos sobre a EAD apresentam acentuado decréscimo, maior, inclusive, do que os referentes ao ensino presencial. Enquanto isso, apenas os relativos à virtualização são representados por curva ascendente.

Portanto, a sistematização dos encaminhamentos concernentes às modalidades de ensino deve incluir a reflexão acerca das relações entre o ensino presencial e o aqui chamado ensino virtual ou em processo de virtualização. Para desenvolver esta reflexão, é preciso assinalar as convergências e as diver- gências que sustentaram a proposta de caracterização e a sua denominação.

A primeira convergência diz respeito à afirmação do distanciamento da escola em relação às demais práticas sociais e à necessidade de buscar alternativas de aproximação. A partir desse ponto, fica configurada uma divergência nas T\&D. Enquanto um grupo propõe a incorporação das TIC às práticas pedagógicas desenvolvidas na escola visando à possibilidade de mudanças significativas, outro grupo põe em xeque essa possibilidade, argumentando que essas mudanças encontrariam obstáculos no sistema regular, representados por questões de ordem paradigmática e por resistências diversas.

Ambos os grupos tendem a abordar questões relativas à presença das resistências, mas o fazem partindo de concepções diferentes e assumem encaminhamentos diversos. Um primeiro grupo, reunido em torno da proposta de redimensionamento do ensino presencial, argumenta que resistências às TIC não podem ser dissociadas do fato de que estas têm sido impostas como soluções verticais que não levam em consideração as condições, a complexidade, o cotidiano, a experiência, os saberes dos professores e alunos, a cultura da escola. Assim, esse grupo tende a propor que as condições concretas dos contextos de utilização das TIC sustentem todos os encaminhamentos nesse sentido, também como alternativa para evitar que as inovações sejam encerradas em práticas antigas, em movimentos de modernização conservadora e de mistificação tecnológica. Assume o contexto escolar como locus da apropriação das TIC, e representa mais de $20 \%$ das produções analisadas.

Um segundo grupo, reunido em torno do questionamento da possibilidade referida, argumenta que as TIC não podem produzir mudanças significativas na educação regular, ante a orientação "instrucionista" da escola. Nesse sentido, afirma que as TIC são incorporadas apenas como ferramentas, pois a escola, como instituição, não dá conta dos novos regimes cognitivos, ainda que alguns avanços possam ser observados, como a substituição da lógica cartesiana do conhecimento em árvore pela lógica do conheci- 
mento em rede. Em outras palavras, as TIC são pensadas como possibilidades de ruptura que, no entanto, não "cabem" nos limites da escola instituída. Daí a sua localização em ambientes de aprendizagem extra-escolares, em diferentes propostas de educação on-line que, somadas, chegam quase a $20 \%$ das T\&D recortadas.

$\mathrm{Na}$ tentativa de sistematizar as duas tendências, é possível afirmar que a referida ao ensino presencial propõe: o redimensionamento do ensino presencial, sem mencionar outro lugar ou modalidade que extrapole as instituições educativas regulares; o investimento na interação professor-aluno, seja na perspectiva afetiva, seja na do compartilhamento da objetividade social; e o fortalecimento do binômio ensino-aprendizagem. Em contrapartida, a tendência à virtualização aponta para: o deslocamento da dimensão presencial para a virtual; uma nova relação educativa na comunidade virtual, estabelecida de "modo espontâneo", rompendo com a assimetria presente na escola; e a quebra do binômio ensinoaprendizagem, privilegiando apenas o segundo elemento do par, pensado como "auto-aprendizagem".

Finalmente, é possível dimensionar as diferenças entre as tendências por meio do deslocamento de um mote conhecido: de não se aprende somente na escola para não se aprende na escola. Pelo menos não da maneira que é possível aprender fora dela, através das TIC. O que implica reconhecer que as T\&D voltadas para a proposição do ensino virtual assumem uma relação peculiar entre educação e tecnologias, que não passa exatamente pela recontextualização das últimas, mas pela reconfiguração da primeira.

\section{Da formação de professores a distância às propostas de e-learning}

Essa representação do território que compreende a incorporação educacional das TIC tem algumas fronteiras demarcáveis. Em um dos extremos, está a alternativa produzida nos anos de 1990: a que restringe as TIC a estratégias de EAD para a FP, como destinação expressa nas políticas oficiais, ${ }^{7}$ e também como demanda induzida de estudos acerca da modalidade a distância. No outro extremo está a produção de alternativas cada vez mais plurais e sofisticadas, para múltiplos fins. Entre as fronteiras, está o ensino presencial, não apenas contando com novas ferramentas ou instrumentos para a realização de seqüências de ensino-aprendizagem, mas com possibilidades de redimensionamento do processo.

A demarcação, por sua vez, suscita questões concernentes às relações entre as modalidades de ensino focalizadas, aos possíveis limites entre elas. Longe de serem simples, esses limites são tornados mais complexos pela possibilidade de utilização de critérios diversos. Em uma tentativa de síntese, é importante sublinhar critérios derivados: dos meios utilizados e dos fins da sua utilização, nas suas relações com os discursos sobre as modalidades de ensino.

Portanto, esta conclusão é marcada pela retomada das relações entre as modalidades. As referentes a ensino presencial e virtual foram, à semelhança da tipificação ensino presencial e a distância, assumidas a partir do locus da utilização. Ambiente foi a palavra-chave aqui assumida como definidora das propostas de virtualização do ensino, na medida da extrapolação do espaço físico da sala de aula e da escola, e, nesses termos, uma objeção pode ser feita. Ela refere-se ao fato de que, também na medida da ruptura com o espaço de lugares, em direção ao de fluxos, o ensino virtual poderia, não só mas também, ser localizado na escola. Entretanto, as T\&D que propõem a virtualização reivindicam uma outra "distância” da escola: a dos padrões assimétricos de interação. Em outras palavras, não é apenas uma questão de lugar e de meios, mas de outro fim, sustentado por outra concepção de educação, centrada na "auto-aprendizagem".

A expressão referida parece remeter a uma espécie de negação do ensino, em atitude coerente com a proposta globalmente considerada. Afinal, trata-se de

${ }^{7}$ Cf. Plano Nacional de Educação. Disponível em: <http:// portal.mec.gov.br/arquivos/pdf/pne.pdf>. Acesso em: 28 out. 2005. 
proposta de ruptura com os padrões criticados na escola, da possibilidade de contar com novos dispositivos pedagógicos, da criação de redes comunicacionais de colaboração e cooperação, como forma de viabilizar novas práticas. Trata-se, em outras palavras, de paradigma educacional emergente, constituído a partir da tecnologia informática como propiciadora de novos regimes cognitivos, apontando para múltiplas possibilidades de aprendizagem, muitas das quais baseadas em movimentos espontâneos que parecem não caber no ensino, ante a intencionalidade e, por conseguinte, a assimetria que o constituem.

Quanto aos limites entre ensino virtual e ensino a distância, até podem parecer resolvidos, na medida em que o segundo tende a ser mais formalizado, destituído de caráter espontaneísta, associado a programas de estudo a serem cumpridos com disciplina, perseverança e atributos afins, além de englobar programas oficiais, alguns deles concebidos e implementados na esfera ministerial. Mas esses limites tornamse mais tênues por conta da crescente sofisticação tecnológica e da sua configuração discursiva.

Do ponto de vista discursivo, uma expressão tem promovido o apagamento das fronteiras aparentemente nítidas: e-learning, como uma forma de aprendizagem em que a mediação tecnológica é destacada. Em português, tem sido traduzida como "educação a distância via Internet" e, de novo, provoca a necessidade de distinguir os dois critérios em jogo: os meios utilizados e os fins da sua utilização.

$\mathrm{Na}$ aplicação do critério definido a partir dos meios, EAD e e-learning podem-se tocar e vazar para o entorno de uma configuração "neotecnicista", através da articulação do que há de mais avançado nas TIC disponíveis no mercado aos preceitos dos anos de 1970: o privilégio dos meios em detrimento das mediações, o corte dos custos, a organização a partir das competências estabelecidas, a corrida para a atualização constante do conhecimento, os pacotes de aprendizagem etc. São movimentos presentes em documentos oficiais e nos discursos de organismos internacionais, como a Organização Mundial do Comércio (OMC). Diante de possibilidades como essa, uma indiferenciação parece promover a necessidade da adjetivação cada vez mais constante dos substantivos da área educacional.

É importante verificar que a história recente da adjetivação dos substantivos relacionados ao ensino (presencial, a distância e virtual) parece ter sido levada ao limite, até que superada pela sua supressão, em nome da aprendizagem. Extrapolando o espaço da escola, em direção a novos ambientes de aprendizagem, acaba-se por adjetivar a educação mesma: acadêmica e corporativa.

Vale destacar que toda essa modalização discursiva, considerando seus pressupostos e implícitos, torna cada vez mais complexa a tarefa de organizar a produção acerca das TIC na FP. Ainda que haja tendências, aproximações e distanciamentos detectáveis, o que está em jogo são concepções diferentes de sociedade e de educação, paradigmas distintos, modos diversos de objetivação, propostas pedagógicas díspares, modalidades variadas, contextos de aplicação específicos.

Finalmente, a perspectiva assumida neste mapeamento, expressa pelo subtítulo "O que foi lido nas teses e dissertações acerca das tecnologias da informação e da comunicação na formação de professores", implica uma indagação: Que outras leituras poderiam ser feitas? É uma pergunta que, ficando sem resposta, traz consigo um convite a outras cartografias.

\section{Referências bibliográficas}

ANDRÉ, Marli E. D. Afonso de (Org.). Formação de professores no Brasil (1990-1998). Brasília: MEC/INEP/COMPED, 2002 (Série Estado do Conhecimento, 6). Disponível em: <http:// www.inep.gov.br/download/cibec/2002/estado_do_conhecimento/ formacao_de professores.pdf>. Acesso em: 28 out. 2005.

BARRETO, Raquel G. Formação de professores, tecnologias $e$ linguagens: mapeando velhos e novos (des)encontros. São Paulo: Loyola, 2002.

BERNSTEIN, Basil. The structuring of pedagogic discourse class, codes and control. London/New York: Routledge, 1990. v. 4. 
FAIRCLOUGH, Norman. Discurso e mudança social. Tradução Izabel Magalhães. Brasília: Editora da UnB, 2001.

FONSECA, Marília. O Banco Mundial como referência para a justiça social no Terceiro Mundo: evidências do caso brasileiro. Revista da Faculdade de Educação, São Paulo, v. 24, n. 1, p. 3769, 1998.

OLIVEIRA, Maria Rita Neto Sales. Do mito da tecnologia ao paradigma tecnológico; a mediação tecnológica nas práticas didático-pedagógicas. Revista Brasileira de Educação, Campinas: Autores Associados; Rio de Janeiro: ANPEd, n. 18, p. 101-107, set./ dez. 2001.

PRETTO, Nelson. Formação de professores exige rede. Revista Brasileira de Educação, n. 20, p. 121-131, maio/ago. 2002.

RAQUEL GOULART BARRETO, doutora em educação pela Universidade Federal do Rio de Janeiro (UFRJ), é professora da Faculdade de Educação da Universidade do Estado do Rio de Janeiro (UERJ). Coordena o grupo de pesquisa Educação e Comunicação, no qual está realizando a pesquisa: "As tecnologias da informação e da comunicação nas políticas de formação de professores: os sentidos da reconfiguração de trabalho-formação docente", financiada pelo Conselho Nacional de Desenvolvimento Científico e Tecnológico (CNPq). Publicou recentemente: Formação de professores, tecnologias e linguagens: mapeando velhos e novos (des)encontros (São Paulo: Loyola, 2002); Tecnologias educacionais e educação a distância: avaliando políticas e práticas (2. ed. Rio de Janeiro: Quartet, 2003); Tecnologia e educação: trabalho e formação docente (Educação e Sociedade, n. 89, p. 1.181-1.201, set./dez. 2004); organização em parceira com Nilda Alves e Inês B. de Oliveira, Pesquisa em educação: métodos, temas e linguagens (Rio de Janeiro: DP\&A, 2005).E-mail: raquel@uol.com.br

GLAUCIA CAMPOS GUIMARÃES, mestre em educação pela Universidade Federal do Rio de Janeiro (UFRJ) e doutoranda em educação na Universidade do Estado do Rio de Janeiro (UERJ), é professora assistente da UERJ, atuando na Faculdade de Formação de Professores, em São Gonçalo. Integra o grupo de pesquisa Educação e Comunicação, no qual participa atualmente da pesquisa "As tecnologias da informação e da comunicação nas políticas de formação de professores: os sentidos da reconfiguração de trabalho-formação docente". Últimas publicações: TV e escola: discursos em confronto (4. ed. São Paulo: Cortez, 2003); TV na escola (In: BARRETO, R. G. (Org.). Tecnologias educacionais e educação a distância: avaliando políticas e práticas. 2. ed. Rio de Janeiro: Quartet, 2003. p. 161-177); Textos contemporâneos da educação: a produção dos sentidos na articulação de linguagens (In: ALVES, N.; OLIVEIRA, I. B.; BARRETO, R. G. (Orgs.). Pesquisa em educação: métodos, temas e linguagens. Rio de Janeiro: DP\&A, 2005. p. 51-62).E-mail: gl.guimaraes@uol.com.br

LIGIA KARAM CORRÊA DE MAGALHÃES, mestre em educação pela Universidade Federal da Bahia (UFBA) e doutoranda em educação na Universidade do Estado do Rio de Janeiro (UERJ), integra o grupo de pesquisa Educação e Comunicação, no qual desenvolve atualmente a pesquisa: "As tecnologias da informação e da comunicação nas políticas de formação de professores: os sentidos da reconfiguração de trabalho-formação docente". Últimas publicações: Programa TV Escola: o dito e o visto (In: BARRETO, R. G. (Org.). Tecnologias educacionais e educação a distância: avaliando políticas e práticas. 2. ed. Rio de Janeiro: Quartet, 2003. p. 105-119); e em parceria com Raquel Goulart Barreto, Modos de incorporação das múltiplas linguagens na formação de professores (In: ALVES, N.; OLIVEIRA, I. B.; BARRETO, R. G. (Orgs.). Pesquisa em educação: métodos, temas e linguagens. Rio de Janeiro: DP\&A, 2005. p. 131-141). Email: ligiakaram@gmail.com

ELIZABETH MENEZES TEIXEIRA LEHER, doutora em educação pela Universidade de São Paulo (USP) e pesquisadora do Núcleo de Tecnologia Educacional para a Saúde, da Universidade Federal do Rio de Janeiro (UFRJ), integra o grupo de pesquisa Educação e Comunicação. Pesquisa em desenvolvimento: “As tecnologias da informação e da comunicação nas políticas de formação de professores: os sentidos da reconfiguração de trabalho-formação docente". Últimas publicações: em parceria com Raquel Goulart Barreto, Imagens das tecnologias: a questão do sentido hegemônico (In: ALVES, N.; OLIVEIRA, I. B.; BARRETO, R. G. (Orgs.). Pesquisa em educação: métodos, temas e linguagens. Rio de Janeiro: DP\&A, 2005.p. 13-22).E-mail: eleher@uol.com.br

Recebido em setembro de 2005 Aprovado em dezembro de 2005 
rando a necessidade de se repensar o sistema educacional, principalmente no que diz respeito às questões curriculares. Destaca a importância do movimento do software livre, enquanto portador de filosofia centrada na cooperação e no trabalho coletivo, ressaltando a importância desse movimento para a educação.

Palavras-chave: tecnologia educacional; educação e comunicação; informática educativa; Internet; tecnologias da informação e comunicação (TIC); software livre.

Technologies and new educations This article analyses contemporary society considering the transformations that have taken place in the realms of science, culture and education. It is considered important to bring culture and education back together and incorporate information and communication technologies (ICT) into them. We examine the progress of ICT as well as the movement towards the monopolisation of the mass media and present work being carried out in the Faculty of Education at UFBA in training teachers. We consider it necessary to rethink the educational system, curricular issues in particular. We highlight the importance of the open source movement as promoting a philosophy based on co-operation and collective work and therefore of great importance to education.

Key-words: teaching technology; education and communication; computer education; Internet; information and communication technology (ICT); open source software

Tecnologías y nuevas educaciones El artículo analiza la sociedad contemporánea, a partir de las transformaciones del mundo científico, tecnológico, cultural, social y educativo, con el objetivo de hacer una crítica a este. Considera importante la reaproximación entre la cultura y la educación, entendidas en el plural, y de éstas con las tecnologías de la información y comunicación (TIC). Aborda los progresos de las TICs y los movimientos de concentración en la propiedad de los medios de comunicación de masa, hace su crítica, y presenta las propuestas en estudio en la Facultad de Educación de UFBA, para la formación de profesores, considerando la necesidad de repensar en el sistema educacional, principalmente lo referente a las cuestiones curriculares. Destaca la importancia del movimiento del sofware libre, en cuanto portador de filosofía, centrada en la cooperación y en el trabajo colectivo, mostrando lo importante que es este movimiento para la educación.

Palabras claves: tecnología educacional; educación y comunicación; informática educativa; Internet; tecnologías de la información y comunicación (TIC); sofware libre

Raquel Goulart Barreto,

Glaucia Campos Guimarães, Ligia Karam Corrêa de Magalhães e Elizabeth Menezes Teixeira Leher

As tecnologias da informação e da comunicação na formação de professores

$\mathrm{O}$ artigo discute os modos de objetivação das tecnologias da informação e comunicação (TIC) na formação de professores. Com base em teses e dissertações defendidas entre $1996 \mathrm{e}$ 2002, analisa elementos e relações visando ao mapeamento de três tendências de incorporação educacional das TIC: como estratégia para o desenvolvimento de diversas propostas de ensino a distância; como possibilidade de aperfeiçoamento do ensino presencial; e como elemento-chave para a constituição de um ensino virtual.

Palavras-chave: tecnologias; formação de professores; modalidades de ensino
The technologies of information and communication in the training of teachers

This text aims to discuss how technologies of information and communication (ICT) are used in the teachers' education. Based on theses and dissertations, defended between 1996 and 2002, it analyses discrete elements and relations with the aim of mapping three trends in the incorporation of ITC: (1) as a strategy to develop diverse distance learning programmes; (2) as a possibility for improving teaching-learning processes; and (3) as the key to e-learning.

Key-words: technologies; teachers' education; teaching modes

Las tecnologías de la información y de la comunicación, en la formación de profesores

El artículo discute los modos de objetividad de las tecnologías de la información y comunicación (TIC) en la formación de profesores. Con base en tesis y disertaciones defendidas entre 1996 y 2002, analiza elementos y relaciones, direccionado a la descripción de tres tendencias de incorporación educativa de las TICs: como estrategia para el desenvolvimiento de diversas propuestas de enseñanza a distancia; como posibilidad de perfeccionamiento de la enseñanza presencial; y como elemento clave para la constitución de una enseñanza virtual

Palabras claves: tecnologías; formación de profesores; modalidades de la enseñanza

Tania Porto

As tecnologias de comunicação e informação na escola; relações possíveis... relações construídas Estamos diante de novas maneiras de compreender, de perceber, de sentir e de aprender, nas quais a afetividade, a imaginação e os valores não podem deixar de ser considerados. Apesar de a es- 